PALAVRAS. Revista de Epistemología, Metodología y Ética del Psicoanálisis

ISSN: 2468-9831

www.revistas.unlp.edu.ar/palavras

palavras@outlook.com.ar

Argentina

\title{
FEMINISMOS Y PSICOANÁLISIS ARGENTINO: EL CENTRO DE ESTUDIOS DE LA MUJER. ENTREVISTA CON MABEL BURIN
}

FEMINISMS AND ARGENTINIAN PSYCHOANALISIS: THE “CENTRO DE ESTUDIOS DE LA MUJER". INTERVIEW WITH MABEL BURIN.

DOI $10.24215 / 24689831 \mathrm{e} 031$

Martin Beltramone

Cómo citar este artículo:

Beltramone, M. (2019). Feminismos y psicoanálisis argentino: el Centro de Estudios de la Mujer. Entrevista con Mabel Burin. Palauras. Revista de Epistemología, Metodología y Ética del Psicoanálisis, 5, 85-107. Recuperado de www.revistas.unlp.edu.ar/palavras 


\section{FEMINISMOS Y PSICOANÁLISIS ARGENTINO: EL CENTRO DE ESTUDIOS DE LA MUJER. ENTREVISTA CON MABEL BURIN}

\section{Martin Beltramone*}

Mabel Burin (nacida en Buenos Aires en 1942) es licenciada en Psicología por la UBA, y doctora en Psicología por la Universidad de Belgrano, de Buenos Aires. Entre 1980 y 1987 formó parte de la comisión directiva fundadora del Centro de Estudios de la Mujer (CEM), uno de los hitos del entrecruzamiento entre psicología, psicoanálisis y feminismos en Argentina. En 2015 obtuvo el título de Doctora Honoris Causa, otorgado por el Instituto de Psicoanálisis de la Sociedad Psicoanalítica de México (SPM). Trabaja como psicoanalista, docente universitaria e investigadora en Estudios de Género y Subjetividad, en la Universidad de Ciencias Empresariales y Sociales (UCES), Buenos Aires. Ha publicado varios libros y numerosos artículos en medios académicos y no académicos. Actualmente es directora del Programa de Estudios de Género y Subjetividad en la Universidad de Ciencias Empresariales y Sociales (UCES), y del Programa Postdoctoral en Estudios de Género de la misma universidad.

E: Martín Beltramone

MB: Mabel Burin

\section{E: ¿Cuál fue el origen del CEM? ¿Cómo aconteció su fundación?}

MB: Bueno, te cuento. Quiénes éramos, qué hicimos...

En los años 70, en Buenos Aires, éramos un grupo de psicólogas que estábamos estudiando cuestiones relativas a las mujeres, con ideas que nos venían de los países del Norte, fundamentalmente Estados Unidos, Gran Bretaña, Francia y España -que estaba pasando por una transición

\footnotetext{
* Facultad de Psicología de la Universidad Nacional de La Plata, Argentina. Mail: martin.beltramone@gmail.com
} 
política, porque había muerto Franco-. Y entonces se produjo un clima de apertura mental, se había formado el Instituto de la Mujer en España - yo desde muy pronto tuve contacto con España y sigo trabajando allá-. Y también sucedió en México, en 1975, lo que se llamó el Año Internacional de la Mujer, que designó una Década de la Mujer, que fue un evento internacional producido por Naciones Unidas, ONU Mujeres.

Yo estaba muy en contacto con esta gente que motivó en mí el interés por las mujeres. Yo era psicóloga, psicoanalista de niños, y estos acontecimientos promovieron en mí un antiguo interés que había tenido porque... yo me recibí a principio de los años 60, soy de las primeras graduadas que tuvo la $\mathrm{UBA}^{1} \ldots$ en este momento hace cincuenta y cinco años que estoy recibida, o sea que formo parte de la historia de la Facultad de Psicología de la UBA (risas). En cuanto me recibí empecé a trabajar con niños. Trabajaba con una psicoanalista que en ese momento era muy conocida, que se llamaba Arminda Aberastury-la negra Aberastury-Yo trabajaba con ella haciendo observación de grupos de madres. Ella coordinaba esos grupos de madres, cuyos niños se atendían con analistas conocidos de ella. Cuando yo hacía esas observaciones ella siempre me decía: "Mirá, Mabel, que detrás de cada una de estas madres hay una mujer que tiene un problema. $\mathrm{Y}$ hay que poder escuchar estos problemas de las mujeres, que no son sólo los problemas como mamás".

Eso fue en el año 64, 65. Ella murió poco después... A mí me quedó esa advertencia. De manera que, en los años 70, con esta movida que surgía en los países del Norte, retomé ese interés que habia tenido, y entonces trataba de escuchar con otra oreja las problemáticas de las mamás de mis pacientes. Por aquel entonces, mujer y maternidad era casi una homologación. Siempre se escuchaba a las mujeres como madre o como esposas, o como amas de casa. Yo quería escuchar otras cosas. Entonces dispuse de una escucha diferencial, que después, en los años 80, se llamó escucha diferencial por género.

\footnotetext{
${ }^{1}$ Universidad de Buenos Aires.
} 


\section{E: ¿Cómo dialogaban estos acontecimientos fundacionales con el panorama sociopolitico local de aquel entonces?}

MB: Acá había una situación de dictadura militar en los años 70. Entonces, fue cerrada la Facultad de Psicología de la UBA, donde yo trabajaba como ayudante de trabajos prácticos. También trabajaba en un lugar que se llamaba Instituto de Orientación Familiar que dirigian dos psicoanalistas, Mauricio Knobel y Jaime Szpilka. Lo llamábamos Instituto de la Familia, era una institución que nucleaba una buena cantidad de psicólogos, psicoanalistas, y hacíamos un trabajo intensivo de formación y también de atención a pacientes. Yo ahí dirigía un área de psicodiagnóstico. En el año setenta y siete los directores se exiliaron: Knobel se fue a Brasil y Szpilka a España, Madrid. Entonces se cerró el Instituto. Quedé sin grupos de referencia, pero tenía un grupo de amigas psicólogas con quienes compartía mis inquietudes.

Con ellas, en 1979 diseñamos unas jornadas multidisciplinarias de investigación que se llamó Ubicación de la Mujer en la Sociedad Actual-un nombre muy lavado pero apropiado para esa época de represión-. Estábamos en esa dictadura militar y teníamos miedo. A estas jornadas, coordinadas por la Lic. Gloria Bonder, se convocó por invitación a gente conocida. Se dieron en el Instituto Goethe, que nos facilitó su auditorio. Todo era bastante precario, había que tomar muchos resguardos... "Cuidado que...", "Fijate a quién...". Pero bueno, todas presentamos ponencias, también los invitados, sobre la mujer en la sociedad actual. No nos habian secuestrado ni matado, ni tuvimos que exiliarnos, entonces nos preguntamos: "¿Cómo queremos vivir, ya que estamos viviendo?». Nos encerramos en pequeños grupos para poder pensar, con nuestras inquietudes, sin claudicar. Te lo digo y me emociono... Marie Langer, una destacada psicoanalista exiliada en México, una vez me dijo: "Mabel, esos fueron los actos de resistencia que tuvieron ustedes"... Bueno, sigo con 1o que te contaba. Las jornadas las coordinó Gloria Bonder, que era la que en ese momento nos coordinaba a todas las que no sabíamos cómo agruparnos. Entonces, a fines del 79 decidimos institucionalizarnos bajo algo que se llamó Centro de Estudios de la Mujer-CEM-. 
Lo formalizamos a principios de 1980. Alquilamos una casa, que era de una persona amiga, quedaba cerca de acá, porque éramos todas psicólogas más o menos de la misma zona, de Palermo, Belgrano y Barrio Norte más o menos. Teníamos miedo de andar mucho por las calles. Éramos mujeres de sectores medios, urbanos, que teniamos nuestros privilegios de clase: éramos mujeres que habíamos estudiado, que podiamos pensar, porque no nos habian secuestrado ni matado. Éramos conscientes de los privilegios que teniamos, y tratábamos de salir adelante con nuestros proyectos. E1 problema era cómo hacerlo, con quiénes, dónde.

En este CEM, tiempo después de haber finalizado las jornadas, habíamos empezado con algo que se llamaba grupos de autoconciencia. Nos reuniamos entre nosotras, las cuatro psicólogas que empezamos en ese momento: Gloria Bonder, que fue la directora inicial del CEM, y las miembros de la comisión directiva: las Lics. Clara Coria, Cristina Zurutuza y yo. Tomábamos como modelo lo que hacian nuestras colegas de los países del Norte, especialmente de las teorías y las prácticas feministas. También teníamos compañeras de México, con quienes estábamos en contacto. Y teníamos, como modelo local, lo que Enrique Pichon-Rivière había desarrollado acá como grupos de reflexión en su Escuela de Psicología Social. Yo había transitado por alli antes de comenzar todo esto, sabía de qué se trataban los grupos de reflexión, y lo aplicamos para esto que era específico para mujeres. ¿Qué hacíamos en los grupos de autoconciencia? Se trataba de reflexionar, en un clima de confianza mutua - necesaria en ese momento tan dificil-. Desarrollábamos temas que habian propuesta las compañeras feministas de otros países, temas que se llamaban las condiciones de vida de las mujeres, que caracterizamos como condiciones de vida opresivas dentro de una sociedad patriarcal. Ese fue nuestro marco inicial. ¿Qué temas, qué problemas entraban? De todo: la conyugalidad, la maternidad - casi todas viviamos en pareja, casadas y/o separadas, todas teníamos hijos-. Así que reflexionábamos sobre las condiciones de la maternidad, de la sexualidad éramos todas heterosexuales, entonces había que analizar cómo habíamos llegado a ser heterosexuales, no nos parecía que nada de eso fuera natural¿Cómo habíamos llegado a ser mujeres de clase media, urbana? ¿Cómo 
habíamos llegado a tener hijos? Tampoco nada de eso era natural. Entonces se trataba de hacer una deconstrucción crítica, sin complacencias, por eso necesitábamos un clima de confianza mutua. Y nuestro trabajo como psicoterapeutas también fue un tema de reflexión, con todos los debates como: ¿incidíamos o no ideológicamente en nuestras pacientes? ¿Reproduciamos los modelos teórico-clínicos, o buscábamos una transformación? Casi todas habiamos leído mucho Freud...

Entonces, en esos años, se transformaron mucho nuestras vidas mientras haciamos los grupos de autoconciencia. En todos los aspectos. En nuestros trabajos cambiamos mucho las maneras de trabajar. Yo cambié mucho con mis pacientas mujeres. Se fueron encontrando con otra analista, mis pacientas me lo decían, yo me sorprendia. Y, en general, era beneficioso. También se transformaron nuestras vidas matrimoniales, nuestra sexualidad cambió muchísimo. Alguna se divorció. Y otras hicimos recontratos dentro de nuestras vidas matrimoniales, tanto para el trabajo dentro de la casa, como la crianza de los chicos, nuestra sexualidad, muchos recontratos... (risas). Por esa época había un compañero en España, que yo conocía bastante, que se llamaba Josep Vicent Marqués, que estaba casado con una filósofa feminista en Madrid, Celia Amorós. Ellos se estaban divorciando por esa época, y él escribió un libro que se llama ¿Qué hace el poder en tu cama?, muy gracioso el título. Lo aplicamos bastante a lo que eran nuestros grupos de autoconciencia.

\section{E: ¿Cuáles eran las lecturas que orientaban la reflexión teórica y personal en estos grupos? Me habias dicho que leian mucho Freud.}

MB: Leíamos... muchísimo. Estudiábamos según una vieja tradición que teníamos de grupos de estudio que también lo aplicamos en el CEM. Leíamos Freud y también muchas autoras de libros que venían de afuera. Me acuerdo de Psicoanálisis y Feminismo de Juliet Mitchell. Analizábamos mucho los textos de la psicoanalista francesa Luce Irigaray. También analizábamos psicoanalistas más clásicas: Michele Montrelay, Piera Aulagnier, Julia Kristeva, en fin. Incluso haciamos, en el CEM, un seminario para psicólogas, que se llamaba Psicologías de la Mujer, que coordinaba 
Gloria Bonder, donde leíamos desde Helene Deutsch y Karen Horney hasta, no sé...psicoanalistas más contemporáneas que habian escrito sobre las mujeres. Muy variado, muy diverso. Leíamos poco de las autoras lacanianas, especialmente de aquellas que se decian feministas, descubriendo que no lo eran.

Teníamos bastante claro para nosotras a qué llamábamos feminismo, que tenía que ver con analizar y transformar las relaciones de poder entre los géneros. $\mathrm{Y}$ al interior de un mismo género. Te digo porque, en esa época, en los grupos de autoconciencia, se había sumado Eva Giberti, y una vez salíamos de las reuniones de grupo, y yo tenía problemas con mi hija mayor, que se estaba volviendo adolescente. Entonces estábamos caminando por la Avenida Cabildo, íbamos a tomar el subte, y yo le contaba: "Mirá lo que me hizo mi hija, mirá, yo la mato...", y entonces recuerdo que Eva me dijo: "Escribí, eso te va a hacer mejor, porque si la matás eso no tiene retorno. Y si lo escribís te va a servir a vos, a otros». Y eso hice. Eso fue a finales del 79 o comienzos del año 80. Entonces hice una terapia vincular de una madre con una hija adolescente, y a través del análisis de este caso pude entender mejor lo que me pasaba con mi hija. Luego lo publiqué ahí en el CEM teníamos publicaciones internas-. Era un análisis para pensar cómo eran las relaciones de poder intragénero, entre una mujer de mediana edad y su hija. Lo llamé Entrecruzamiento entre Dos Crisis-la crisis de la mediana edad en la madre con la crisis de la adolescencia en la chica-. Escribí el caso clínico y lo analicé como relaciones de poder. Y lo llevé a un congreso que hubo, en 1981, organizado por la Asociación Argentina de Psicología y Psicoterapia de Grupo $^{2}$. Fue un congreso único, multitudinario, que nos reunió a todos los que quedábamos que no habíamos sucumbido a la dictadura militar. Y entonces yo llevé este análisis que llamaron de un grupo familiar binomial.

E: ¿Cómo fue esa experiencia de reencuentro, teniendo en cuenta las dificultades que habia durante esa época para llevar a cabo reuniones multitudinarias?

\footnotetext{
2 De ahora en adelante: AAPPG.
} 
MB: Yo quedé sorprendidísima de cuánta gente vino a mi exposición. Había gente sentada en los pisos... "¿Qué pasa acá?" pensaba. Y no era solamente por la alegría del reencuentro, de saber que todavía estábamos vivos y pensando, sino también porque había algo nuevo para decir, que era en clave de relaciones de poder. Vino a escucharlo tanta gente, nos pasaron a un aula más grande y aun así no cabíamos... Ahí me di cuenta que algo de ese clima empezaba a cambiar, por el interés que había en analizar las relaciones de poder.

Yo era una de las voceras que podia expresar ese cambio, porque me animaba un poco más, no sé... También creo que había que tener rasgos de personalidad en ese momento, que permitieran semejante exposición... Había unos rasgos establecidos de ser psicóloga mujer en esa época. Éramos muchas psicólogas mujeres ya en aquella época. Había un rasgo común que entraba dentro de lo que se llamaba en psicopatología la histeria, era el rasgo bienvenido en el modo de ser psicóloga. Podía ser una histeria estilo de angustia - tipo fóbica: tímida, recatada, discreta- o podías ser más conversiva-más demostrativa-. Y había que pivotear entre cada una, porque si eras medio obsesiva o medio esquizoide, esos eran considerados rasgos masculinos y entonces te decian que eras fálica. Pero yo me la bancaba.

Había un deber-ser muy fuerte, muy marcado, había pautas para ser creíble, respetable. Por eso en el CEM, cuando empezamos a salir públicamente después del 83 y 84, luego del descongelamiento político, teníamos un lema: parecer respetables, parecer decentes. ¿En qué consistía? Por ejemplo, teníamos códigos de vestimenta para salir a los congresos y jornadas: usar trajecito, con chaqueta y falda, y no pantalones como se acostumbraba, no teníamos que usar tanto pantalón porque si no éramos sospechosas de fálicas y masculinas...

En esa época yo iba mucho a la televisión. Yo hacía mucha difusión de estos temas en varios programas donde me invitaban. Por eso te decía, si de algo no tenía era miedo de hablar, de expresarme. Había un programa de cable que conducía Mónica Gutiérrez, muy compañera de nosotras. Ya por esa época ella se definía como periodista feminista, y tenía mucha exposición 
pública. Se llamaba Las Unas y los Otros, a lo mejor a ella le quedaron registros de aquellos programas. También estaba el de Anna María Muchnik, que tenía un programa en los 70 que se llamaba Buenas Tardes, Mucho Gusto, ella tenía mucha afinidad con pensar estas cuestiones de las mujeres.

En fin, yo estaba sorprendida porque era mucho más gente que a la que estábamos acostumbradas en el CEM, porque, aunque hubiéramos incorporado gente en el 80, 81 —algunas compañeras psicólogas de La Plata se acercaron más o menos por esa época-, no era una institución a la que se acercara la gente que pasaba por la calle, era solamente por invitación. Aunque luego se sumaron antropólogas, abogadas, porque el espíritu del CEM era multidisciplinario.

\section{E: ¿Habia entre las miembros del CEM alguna psicóloga que adscribiera a una orientación teórica no específicamente psicoanalítica?}

MB: Creo que no. En esa época, en Buenos Aires, por fuera de la formación psicoanalítica no había casi gente. Pero sí teníamos algún intercambio con gente que estaba con este tipo de inquietudes, pero desde otras perspectivas. Por ejemplo, recuerdo a una compañera psiquiatra, de mediados de los 80 , que venía del campo de la psicología sistémica, María Cristina Ravazzola. Luego había otras compañeras, con orientación de la psicologia sistémica, que trabajaban en un instituto sobre familias. Teníamos bastante intercambio con ellas. Yo recuerdo que muy a menudo me invitaban para que planteara cuestiones que enlazaran psicoanálisis y teoria feminista. Hacian jornadas y congresos. Te digo de ellas porque me llamaban por este tema de la madre y la hija adolescente, que les parecía original y entonces querian escuchar de qué se trataba.

Después, por esa época también se incorporaron Irene Meler, por el 81, Ana María Fernández, Marta Rosenberg-una médica psiquiatra que está coordinando la Campaña Nacional por el Aborto-. Ella sabía más sobre Lacan, entonces nos explicaba cosas de esa escuela. Aunque no coincidiamos mucho, invitábamos a gente de escuelas lacanianas también. 


\section{E: ¿Se siguieron coordinando con asiduidad desde el CEM jornadas multidisciplinares, siguiendo el modelo de las primeras jornadas de $1979 ?$}

MB: Eran anuales. Se hacían en la casa donde funcionaba el CEM, que tenía tres o cuatro habitaciones -una era más grande y allí haciamos el plenario-. Eran jornadas de poca gente, no más de cincuenta personas, era más entre nos. Hacia el 88 o 89 ya eran jornadas más numerosas, probablemente habia más de cien personas, creo que fue la última que se hizo. El objetivo de las jornadas siempre era buscar la difusión de nuestros trabajos para legitimar nuestras ideas, también relacionarnos con otras instituciones, como la Asociación de Terapia Familiar, la AAPPG y otras instituciones feministas, como Lugar de Mujer, ATEM ${ }^{3} \ldots$

Después, en el 82 hubo un descongelamiento político mayor, y entonces se empezó a acercar más gente al CEM. Venía gente de otros países a conocerlo. Ya las prácticas feministas estaban más difundidas, entonces venian a ver que era este bicho que había en Buenos Aires, donde había tantas psicólogas.

\section{E: ¿Tenia el CEM vinculación con personas e instituciones extranjeras?}

MB: En la época del CEM yo tenía contacto con algunas colegas mexicanas, que tenían mucha actividad en el tema de Estudios de la Mujer. Entonces desde los 80 yo comencé a viajar, no por el CEM, a México para dar seminarios, conferencias. Con Gloria Bonder fuimos al II Encuentro Feminista Latinoamericano y del Caribe, en Lima, en el 82 u 83, y ahí sí dimos a conocer trabajos del CEM. En enero del 88, luego de la publicación de mi libro Estudios sobre la subjetividad femenina. Mujeres y Salud Mental, me invitaron desde el Instituto de la Mujer en España, para presentarlo y dar conferencias. Y bueno, hasta el dia de hoy mantengo intercambios muy fluidos, con México y España, donde viajo todos los años para dar seminarios, supervisiones, etc.

\footnotetext{
${ }^{3}$ Asociación de Trabajo y Estudio de la Mujer.
} 


\section{E: ¿Qué otras aperturas de programas de actividades se dieron en el CEM en aquella época, posibilitadas por el descongelamiento politico?}

MB: Empezamos a hacer investigaciones, no solamente seminarios. Por esa época Clara Coria empezó a hacer grupos de reflexión sobre las mujeres y el divorcio, el dinero. Hay un libro de Clara que publicó en el 86, se llama $E l$ sexo oculto del dinero. Tuvo muchas reediciones, mucha circulación, con un matiz singular: tenía un tono de divulgación de estos conceptos que trabajábamos en el CEM. Ese libro entraba dentro del clima de la época en denunciar las condiciones opresivas de la vida de las mujeres porque se refería a la cuestión del dinero y la pareja. Ella estaba analizando estas cuestiones en mujeres de clase media urbana, en parejas heterosexuales.

\section{E: Entiendo que, con esta vertiente de los grupos de reflexión abiertos a la comunidad, podria decirse que el CEM tenia una rama de actividades de extensión.}

MB: Sí, así, era extensión. Y bueno, también hacíamos supervisión entre nosotras, para ver cómo aplicábamos todo esto que estudiábamos en nuestros trabajos como terapeutas. Y hacia mediados de los 80 también se empezaron a acercar algunos compañeros varones, que se preguntaban: "¿qué hacemos nosotros con el género masculino? ¿Existe o no?».

\section{E: ¿Cómo se confeccionaban los programas de actividades docentes y de investigación que tenian lugar en el CEM?}

MB: Cada una decía que tema prefería. No había organización tipo cátedra de la facultad. Se decía: "yo voy a hacer tal grupo tal día, a tal hora, no me ocupen la habitación". Y había una secretaria que más o menos organizaba todo eso. Era todo muy casero y espontáneo, con bastante improvisación que haciamos sobre la marcha, a pesar de que tratábamos de ser ordenadas y organizadas lo más que podiamos. Al principio nosotras invitábamos a la gente a que viniera a nuestros seminarios y talleres de reflexión, que nos 
conocía de otros espacios de docencia e investigación. Muy autogestión, en nuestro funcionamiento. No teníamos un cronograma rígido, lo armábamos sobre la marcha, de acuerdo con nuestros intereses.

También teníamos programas de asistencia psicológica comunitaria... Pero algunas cosas eran más lo que proponiamos que lo que efectivamente se nos daba. Más bien tratábamos de llegar a esos lugares, por ejemplo, en espacios comunitarios. Quizás algunas de mis compañeras tuvieron alguna injerencia en la formación de líderes comunitarios, pero no sé en qué quedó luego... Por otro lado, el área de difusión, quizás era un área que no funcionaba muy bien. A veces haciamos reuniones para organizar, pero no lo lográbamos como queríamos.

\section{E: Respecto a los trabajos que fueron el producto final de la investigación llevada a cabo en el CEM, ¿cómo fue la recepción que tuvieron en aquel momento?}

MB: Bueno, en un momento de la trayectoria nos dimos cuenta que no habíamos problematizado qué pasaba con los varones del mismo modo que lo habiamos hecho con las mujeres. Y a veces notábamos reacciones violentas de parte de algunos varones hacia nuestros estudios. Eran muy pocos los varones solidarios que aceptaban nuestras hipótesis y nuestras teorias.

En general, por aquella época recibiamos burlas y actitudes descalificatorias en las instituciones psicoanalíticas. Lo más común es que de alguna forma más o menos disfrazada nos dijeran que éramos mujeres fálicas, o masculinas y poco femeninas, por lo ambiciosas. Una interpretación muy al sesgo de la época.

A mí, la verdad, es que esas cosas nunca me importaron mucho, yo seguía adelante con mis proyectos. En todo caso, eso que decían me llevó a preguntarme qué les pasaba. Algunas compañeras quedaron afectadas por las críticas de sus maridos y compañeros de trabajo, y dijeron: "Yo no sigo con esto, me hace mal. Perjudica mi carrera laboral. Piensan que hago ideologías feministas al interior del consultorio". A mí no me importó hacer entrar en crisis mi vida familiar, mi vida laboral. Me sentía acompañada por 
muchas otras colegas. Y cada vez fui ganando más consenso, sobre todo de aquellos psicoanalistas que estaban en la cuestión de Derechos Humanos, con la llegada de la democracia. Yo traté de hacer alianzas con esos grupos, por ejemplo, mediante Eva Giberti, que estaba en la Asamblea Permanente sobre los Derechos Humanos. Pero bueno, volviendo, te decía que las teorías y prácticas feministas, y luego los Estudios de Género, crearon resistencias en esas décadas en el ambiente psi.

\section{E: ¿Cómo era la relación con las instituciones psicoanaliticas que mencionás?}

MB: Las instituciones claves eran $\mathrm{APA}^{4}$ y APdeBA ${ }^{5}$. Habia algunas otras instituciones no tan numerosas ni hegemónicas, como la Asociación Argentina de Psicología y Psicoterapia de Grupos, y la Escuela de Psicoterapia para Graduados, que eran mucho más flexibles y admitian más multiplicidad teórica y disciplinar. Las otras... a lo sumo incorporaban algunos conceptos de la filosofia, de alguien como Julia Kristeva, por ejemplo. Entonces, esos autores filósofos franceses que iban al psicoanálisis eran aceptados. Al resto ellos los llamaban extraterritoriales, y hacian como un alambrado del territorio, donde uno quedaba como un invasor, parecía que uno quería introducirse alli sin autorización... Había marcadas relaciones de poder, muy jerárquicas. Para las instituciones psicoanalíticas clásicas hegemónicas yo no tenía el título de analista, yo era psicóloga, y hereje, porque pensaba en clave de género. En un momento, en los años 80, me invitaron a inscribirme como alumna de sus seminarios, es decir, que yo ahora podía ocupar uno de los poquísimos cupos para entrar a esas instituciones. Para mí fue casi ofensivo. No lo acepté de ninguna manera, porque veía las relaciones de poder que se jugaban en esas instituciones. Incluso algunas de esas personas que formaban parte de esas instituciones habian venido a estudiar conmigo, en mi consultorio, pero parecía que lo hacian clandestinamente. Yo coordinaba seminarios de formación privadamente cuando cerraron la Facultad de Psicología, donde yo era

\footnotetext{
${ }^{4}$ Asociación Psicoanalítica Argentina.

${ }^{5}$ Asociación Psicoanalítica de Buenos Aires.
} 
docente, pero en ese momento ninguna de esas psicoanalistas decía que estudiaba con Mabel Burin.

Entonces, con las instituciones psicoanalíticas hegemónicas, las relaciones eran pocas y malas, de desconfianza. En los 80, calamitosas. En los 90, hubo un poco más de acercamiento. Había una psicoanalista en la APA, Mariam Alizade, buena amiga e interlocutora mía, que estaba muy interesada en las cuestiones de las mujeres. A fines de los 90 ella habia organizado un área en la APA, y tenía cierto prestigio adentro de esa institución. Y nos invitaba a hablar sobre feminismo... Quizá no estábamos muy de acuerdo, pero eran políticas de alianza. De cualquier manera, yo nunca fui de esas personas que quieren que todos recemos el mismo rezo. Por eso siempre me acerqué a gente con otras ideas, que pudiera aportar algo novedoso.

Entonces, hacia fines de los 90, la APA empezó a abrirse un poquito a los temas de las mujeres, a través de Mariam Alizade. Ella ya murió. Era una analista con una mentalidad más abierta. Se había puesto en contacto con la asociación psicoanalítica de Estados Unidos, donde se empezaba a admitir que sus analistas incorporaran los aportes de los Estudios de la Mujer. Entonces ella importó de allí el criterio de legitimación de estas problemáticas. También tenía contacto con México, donde los Estudios de la Mujer tenian muchísima más difusión que acá, te contaba, por la Década de la Mujer -bueno, acá en Buenos Aires muchas de nosotras fuimos hijas de esa década-. Ella nos invitaba para que habláramos en sus seminarios en la APA. Pero allí nos decían que lo que pensábamos era ideológico, que era extraterritorial, que no era psicoanalitico...

\section{E: Habia que ir con capa y espada.}

MB: Bueno, esas son figuras medio fálicas... Digamos que había que ir con buena onda. Había que poder tolerarlo. Muchas quedaron al costado del camino, porque las críticas más duras, al menos para mí, apuntaban muy sensiblemente a nuestras vidas privadas. Eran del estilo de "te preocupás mucho por las mujeres, y miralas a tus hijas como están", o "te preocupás mucho por el trabajo de las mujeres, y mirá el tuyo", o "cuidá mejor tu 
matrimonio que se te está yendo a la mierda". Y nuestros hijos y familias tenían problemas como cualquier hijo de vecino, pero esto era de parte de otros profesionales, incluso de nuestros propios analistas. O sea, se nos hacía responsables de lo que sucediera en el hogar, en los vínculos familiares. Era el clima de la época, el clima emocional, dificil, que ya no era solamente el sesgo de la dictadura militar —el miedo, que, por supuesto, no era poco-, era otro, distinto, que se aplicaba a nosotras por ser psicoanalistas con formación feminista.

Te lo cuento en primera persona, cómo se daba este terrorismo intimo, que incluso se vivía dentro del dispositivo psicoanalítico. Desde el propio analista, pero también desde las propias pacientes. Muchas no lo soportaron, decían: "Me desvié de hacer una vida en común con mi marido por estar pensando en estas cosas». Es una secuela del terrorismo de Estado, pero quizás lo hubo mucho antes y no teníamos conciencia. Y, de hecho, la dictadura militar no terminó con la llegada de lo democracia, sino que este terrorismo siguió en los niveles micro. Estas son reflexiones políticas, que yo llamo politica de las subjetividades, es un criterio de la política distinta de las políticas públicas o las institucionales, se refiere al impacto de las relaciones de poder sobre nuestras subjetividades. Las tengo que tener en cuenta como analista, para saber de dónde vienen determinados sentimientos de agobio, de miedo, de tristeza, que sentian estas analistas cuando decían: "No puedo seguir». Hablamos entonces de un clima emocional terrorista, que hoy en día se presenta quizás en mucho menor medida.

\section{E: En medio de este clima emocional de dificultad, ¿cómo creés que se fue construyendo la legitimidad del trabajo intelectual realizado en el CEM?}

MB: Para mí la legitimación de mi trabajo intelectual se basó más que nada en el reconocimiento de mis pares colegas, no de las grandes instituciones que antes te mencionaba. Lo mío no era por ahí, sino por el reconocimiento entre mis pares a través de mis libros. Entonces, insistía mucho en publicar y escribir para que quedara bien asentado mi pensamiento. Eso en los 
primeros años. Luego se fue dando el reconocimiento y legitimación en el ámbito público más amplio.

Una vez me invitaron de la APA, en los 80, y yo hice mi presentación con un corte por género. Un señor del público se levanta y dice: "Soplan aires feministas en esta sala". Entonces le dije: "Gracias por el reconocimiento, y no tema que estos aires se vuelvan ventarrones" (risas). Nosotras teníamos debates sobre cómo tenían que ser nuestras presentaciones pensando en una revolución. Pensábamos en la revolución silenciosa de las mujeres, un término que viene de los países del Norte, cuando entendiamos el temor que sentía mucha gente ante el feminismo que podría ser subversivo o terrorista, términos que marcaban la sociedad en aquella época. ¿Qué clase de revolución sería la nuestra? Algunas formas subversivas nos producian rechazo, rechazábamos cualquier forma de violencia, la habiamos padecido mucho durante la dictadura militar. Entonces nuestra forma de revolución no sería con violencia. Nosotras considerábamos que la revolución silenciosa de las mujeres había sido la única revolución pacífica que había tenido éxito en el siglo XX, y no como la bolchevique o la cubana, por ejemplo, que habían sido muy sangrientas. Hoy la revolución de las mujeres es de las más jóvenes, que son más bullangueras (risas). Nosotras éramos más silenciosas y discretas, pero no menos eficaces. Ahora se expresan de otra manera, son otras formas, pero el objetivo feminista de transformar nuestros modos de vida sigue intacto.

\section{E: ¿Establecia el CEM relaciones con algún sector de militancia politica?}

MB: Yo tuve cierta militancia politica en la adolescencia, y luego en la Facultad, que me aportó algunas ideas acerca de cómo debían orientarse relaciones sociales más justas. Luego me aparté. Pero en los grupos de reflexión del CEM, aunque no teníamos un perfil político militante claro, entendiamos que nuestra actividad tenía un posicionamiento, y no de cualquier modo, poniendo el acento en el problema de las desigualdades e inequidades de género. De cualquier manera, nos invitaban de reuniones de militancias políticas, e íbamos. También asistí por esa época al primer 
Encuentro Nacional de Mujeres en el Teatro San Martín, en el año 85, yo llevé para exponer algo de Estudios sobre la Subjetividad Femenina. Como podrás apreciar, acá hay mucho de pionerismo, de primera vez, en estas trayectorias que fui haciendo.

\section{E: ¿Hubo algún acercamiento de colegas varones al CEM? Volviendo a esta cuestión resistencial que atribuiste a algunos de ellos...}

MB: Sí, te decía que provocaba sentimientos adversos. Entonces decidimos que, en vez de pelearnos con ellos, íbamos a estudiarlos, como hacíamos siempre que se nos presentaban cuestiones así. Y así, bien entrados los años 80, se nos sumaron colegas varones, interesados por problemáticas del género masculino. Recuerdo en particular a uno de ellos, Luis Bonino Méndez, que en el 85 migró a Madrid, y allá fundó el Centro de Estudios sobre la Condición Masculina, con ejes de análisis como la paternidad, la sexualidad, la violencia y el trabajo masculinos. Él fue uno de los pioneros en este tema en España.

\section{E: Respecto a los últimos años del CEM, ¿cómo aconteció su cierre?}

MB: Por el 85, ya en democracia, entramos a la UBA, cuando se intentó normalizar la Facultad de Psicología. En el 84 hicimos allí un seminario de posgrado sobre estos temas respecto de la mujer, y en el 87 se creó una carrera de especialización en Estudios de la Mujer. Allí ya no estuve yo, ya estaba más apartada, pero alguna gente del CEM sí participó, o sea que los derivados en docencia del CEM se formalizaron en esta carrera de especialización, que dirigió Gloria Bonder, e incorporó a Cristina Zurutuza y a Irene Meler. Ya para el 86 el CEM se había desarrollado muchísimo. Se había abierto mucho al ámbito público.

Por ese año empecé a apartarme. Hubo cismas en el CEM. Tuve algunos desacuerdos con la orientación que iba tomando. En el CEM hubo cierta horizontalidad, pero no tanta. Se conservaban jerarquías, y no éramos ciegas a eso. Incluso eso fue lo que provocó el alejamiento de varias de nosotras dentro de la institución: el malestar por diversas actitudes jerárquicas y 
autoritarias. Sabíamos que uno de los momentos más difíciles de los grupos de mujeres era un momento inicial de mucha idealización del grupo y de mucha identificación entre todas, entonces luego fue muy doloroso marcar esas diferencias, y no pudimos superar las diferencias con jerarquías.

En el 87 publiqué Estudios sobre la Subjetividad Femenina, un libro con los trabajos que había escrito mientras estaba en el CEM, acompañada de colegas del CEM que publicaron allí también algunos capítulos. Para mí era muy evidente que yo ocupaba una posición de cierta ascendencia con respecto a estas compañeras que figuran en la portada de Estudios sobre la Subjetividad Femenina, que eran más recién llegadas.

\section{E: En lo tocante a la producción teórica de tu autoria durante tu estadia en el CEM, algo que me pareció central durante la lectura de Estudios sobre la Subjetividad Femenina es el re-enfoque sobre las vicisitudes del deseo de un hijo en el psiquismo femenino.}

MB: Sí, yo allí lo llamo de la ampliación del repertorio deseante. Está intimamente relacionada con una categoria original, el deseo hostil, que parte de un uso específico de la teoría pulsional-deseante de la teoría psicoanalítica. En general la mayoría de los autores que parten de los textos freudianos para entrecruzar con los Estudios de Género utilizan la teoría de las identificaciones tempranas y también la de la construcción temprana del narcisismo. A mí me interesó la teoría pulsional-deseante, porque me interesaba responder a la pregunta que Freud se hace en La Sexualidad Femenina: ¿qué desean las mujeres? Entonces me puse a estudiar sobre cómo se pueden construir los deseos de las mujeres por fuera de las identificaciones tempranas. Entonces tomé, más que nada, el texto Pulsiones y sus Destinos. Y allí me interesó ver los aspectos de las pulsiones amorosas y las hostiles, en el momento de la defusión, qué destino tienen. Entendi que algunas, según Freud, tienen un destino de desarrollo de afectos, y otras, de deseos. Y entonces lo entrecrucé con lo que había aprendido de las teorias feministas, sobre cómo el patriarcado influencia devenires distintos: para las mujeres, las pulsiones amorosas desarrollaban deseos amorosos y afectos tales como la abnegación, la postergación de sí misma, la generosidad, etc., 
necesarios para la constitución de la familia nuclear. Es decir, que las mujeres deseen cuidar, amar y proteger a sus hijos y sus maridos, en el contexto del amor romántico. Esto era consistente con el desarrollo del patriarcado en un momento histórico que es la revolución industrial y la revolución francesa. Entonces nace la división sexual del trabajo: que los varones puedan ir a trabajar a la industria, ser proveedores económicos de la familia, y vuelvan a la casa a hacer lo que se llamaba el reposo del guerrero. Entonces se construye un sistema superyó-ideal del yo específico para las mujeres: el ideal maternal, como ideal constitutivo de la subjetividad de las mujeres. Y esto la colocaba en lugares de exclusión en el espacio público. El patriarcado pre-moderno era distinto, este que te hablo es el patriarcado capitalista. Y eso llevo a que en el 1900 Freud encontrara a las mujeres histéricas y deprimidas. A Freud le llamaba la atención cómo en un momento de la vida se detenían sus movimientos libidinales. Eso es lo que más tarde llamamos la crisis de la mediana edad. Y esto se refería fundamentalmente al trabajo reproductivo. Por supuesto, no planteo relaciones causa-efecto estrictas, sino coexistencia de una cosa con la otra.

A mucha gente no les gusta el concepto de deseo hostil. Les molesta especialmente a las mujeres psicoanalistas. Me dicen: “¿Por qué llamarlo hostil?». Lo equiparan con el desarrollo de afectos tipo celos, rivalidad, envidia, les parece falocéntrico. Yo lo llamé como lo llama Freud... pero, ¿quieren llamarlo de otra manera? Está bien, que lo hagan, para mí se refiere a un deseo de recortamiento, de diferenciación del/la otro/otra.

\section{E: ¿Cuáles fueron los destinos de tu trayectoria de investigación luego de tu partida del CEM?}

MB: En el 90, con Susana Velázquez y Esther Moncarz publiqué luego un libro que se llama El malestar de las mujeres. La tranquilidad recetada. Es sobre estados depresivos y sobre el consumo y abuso de psicofármacos en mujeres, que es un tema que todavía me siguen pidiendo que dé, por ejemplo, cuando voy a México. 
Por esa época hubo algunos cambios de clima social y subjetivo. En los años 90 ya llevábamos algunos años de prácticas democráticas, entonces hubo una apertura a pensar de otras maneras posibles, no sólo desde el binarismo de género. Entonces, si en los 80 el CEM sólo trabajaba un feminismo centrado en las mujeres - el criterio era la opresión femenina-, en los 90 me comencé a preguntar cuál es ahora el sujeto del feminismo, ya que se abria a pensar la existencia de subjetividades ya no construidas de manera binaria. Entonces, empezamos a pensar en clave de relaciones de poder entre los géneros, especialmente en aquellas en las que denunciábamos la desigualdad. Relaciones de poder entre géneros, entre sujetos hegemónicos y otros subalternos, pero también al interior de un mismo género. Eso fue un viraje que hicimos más hacia el final de los años 90 . Aunque debo reconocer que hasta el día de hoy mantenemos los binarismos de género, especialmente en la universidad. Para hacer accesible y sostenible un programa sobre estudios de género dentro del discurso universitario hay que construir un discurso desde el binarismo. Podríamos llamarlo una estrategia de supervivencia, quizás.

En el 95 comencé a participar del Foro de Psicoanálisis y Género, fundado por Débora Tajer e Irene Meler en APdeBA. Allí participé desde el primer momento con conferencias, participaciones en paneles y también en la organización de jornadas. Posteriormente, cuando se organizó el Curso de Psicoanálisis de Género - dependiente del Foro, que es un curso anual que se realiza hasta el día de hoy - allí comencé a dar clases. Allí doy clases sobre qué es el género y cómo aplicarlo a la teoría psicoanalítica, sobre psicopatología de género y sobre la escuela argentina en psicoanálisis y género, y hacia el final doy un ateneo clínico en donde analizamos algún caso desde esta perspectiva. También he participado en otras actividades, algunas de extensión, así como en la escritura de algunos capítulos de libro.

Luego, en el 95 o 96 entramos con Irene Meler en la Universidad Hebrea Argentina Bar Ilán, donde nos pidieron que diéramos un seminario sobre género $\mathrm{y}$ familia. $\mathrm{Y}$ como resultado de esa formación que dimos allí publicamos este libro en el 98: Género y Familia. Poder, Amor y Sexualidad en la Construcción de la Subjetividad. En el 96 había publicado otro libro, que compilamos con Emilce Dio Bleichmar, titulado Género, Psicoanálisis y 
Subjetividad. Las autoras son compañeras que estaban también en el CEM. Y en el 2000 publicamos este otro libro con Irene Meler: Varones. Género y Subjetividad Masculina, que también se desprendió de seminarios que dictamos en esa universidad que te conté.

Con la crisis del 2001, la Universidad Hebrea Argentina Bar Ilán cerró, y pasamos a esta universidad en la que estamos hasta ahora, la Universidad de Ciencias Empresariales y Sociales (UCES), con un programa que llamé Programa de Estudios de Género y Subjetividad. Alli hacemos investigación, docencia, publicaciones, jornadas, etc. Una de las investigaciones fue Género, Trabajo y Familia, y publicamos sus resultados en 2004 un número monográfico de la revista Subjetividad y Procesos Cognitivos de la UCES. En el 2007 hicimos una investigación sobre Precariedad Laboral y Crisis de la Masculinidad. Impacto sobre las Relaciones entre los Géneros, con grupos multidisciplinarios de otras universidades, para lo cual también hicimos encuentros, jornadas, y sus resultados salieron publicados en otro libro. Y luego publicamos varios números de la Revista Científica de la UCES.

En estos dieciocho años en UCES organicé, primero, un Diplomado en Estudios de Género, que luego pasó a ser una Maestría en Estudios de Género. Y también dirijo un Programa Posdoctoral en Estudios de Género, y que recibe a mucha gente de Colombia, México, Brasil, Chile, o sea, un Programa Postdoctoral que tiene un amplio impacto en América Latina. Cada dos o tres años reúno todos los trabajos postdoctorales y los publico en un número monográfico de la Revista Científica de la UCES.

Más recientemente, con Irene Meler, Juan Carlos Volnovich y Débora Tajer, nos convocaron desde Topía para escribir para este libro, sobre La Crisis del Patriarcado. Mientras tanto, desde la UCES yo había firmado un convenio con la Universidad Nacional Autónoma de México (UNAM) desde donde hicimos investigaciones conjuntas y publicamos estos libros. También habia firmado un convenio con el Instituto de Estudios de la Mujer de la Universidad de Valencia, con intercambio de docentes, investigaciones, publicaciones.

Por otro lado, desde hace muchos años doy clases y conferencias sobre género en la Sociedad Psicoanalitica de México (SPM). Las directoras de la Sociedad Psicoanalitica de México (SPM) vinieron a hacer la trayectoria 
postdoctoral en Estudios de Género, acá en Buenos Aires, y con ello ahora encuentran más fácil incorporar los Estudios de Género en la formación de los psicoanalistas. En el 2015 en esa institución me dieron una distinción de Doctorado Honoris Causa, porque yo, en 1993, me doctoré en Psicología Clínica. La pregunta que orientó la elaboración de mi tesis fue por el devenir de la crisis de la mediana edad. Descarté allí la hipótesis del nido vacío, y también la del déficit estrogénico como generadoras de los estados depresivos entre las mujeres de mediana edad. Y encontré que, en muchas mujeres entrevistadas, era compartido el hecho de encontrarse con el techo de cristal en sus carreras laborales, y que eso operaba como factor depresógeno. El trabajo y ganar el propio dinero en el ámbito extradoméstico en esas mujeres de mi investigación doctoral operaba como un factor de protección contra los estados depresivos, y me encontré con que en estas mujeres en verdad había algo en sus trabajos que era un factor depresógeno, porque se encontraban con el techo laboral en sus carreras laborales. En los 90 acá no hablaba nadie de este tema. Inmediatamente lo publiqué como capítulo de un libro, y en varios medios de difusión masiva.

Estas son algunas cosas que me dejó el CEM en materia de vínculos. Esto es herencia del CEM, por las reflexiones y las compañeras que me procuró, y que sigo manteniendo aún ahora.

\section{E: Para finalizar, ¿cuáles te parece que fueron los alcances y límites de la propuesta del CEM como institución dedicada al abordaje multidisciplinar de los Estudios de la Mujer?}

MB: Los vínculos con mis colegas, con sus encuentros y desencuentros, fueron para mí los hechos de mayor alcance, cómo han marcado un antes y un después en mi vida. Por una parte, armar redes de estudio y de amistad con ellas. Luego, la dolorosa comprobación de que entre las propias mujeres hay también diferencias y desigualdades. Nuestra condición de clase, de etnia... ¿qué pasa con las mujeres de otras etnias, como de los pueblos originarios, o migrantes? Me sorprendió mucho, en las manifestaciones por el aborto en el Congreso, me encontré con una bandera que decía Movimiento Indigenista. Y me quedé pensando y dije "¿Dónde figuran estas 
personas en nuestras teorias y prácticas?". Muchas de las que fuimos pioneras aquí, o en México, o en Estados Unidos, se nos critica algo: que hablábamos solamente sobre mujeres de clase media urbana, heterosexuales. Lo cual es correcto, pero ese era el contexto de la época que posibilitó que surgieran este tipo de ideas. Todavía no habían surgido los así llamados feminismos populares y otras modalidades feministas que encontramos poco después; en ese sentido, no teníamos con quien contrastar nuestras ideas. Y también, por otro lado, el psicoanálisis no estaba interesado en algo que fuera más allá de la gente de los sectores medio urbanos, ni en las mujeres con este criterio de análisis de opresión de género. Y, de hecho, para ese psicoanálisis, muy tradicional, nosotras éramos herejes.

También el feminismo se encuentra atravesado por las diferencias etarias. En estas manifestaciones también hay mucha gente joven. Te cuento una anécdota que me ocurrió en la marcha en la plaza del Congreso por el debate sobre el aborto. Yo iba caminando con mi pañuelo en la cabeza, porque lloviznaba, y veía que me sacaban fotos, me llamó la atención, pero seguí caminando. $Y$ entonces se acercan unos chicos jovencitos, que me seguían con una filmadora, cuando les pregunté por qué me seguian me explican que era la única persona tan mayor que habian visto en toda la manifestación. Después me encontré con más colegas, pero me quedé pensando... ¿Qué pasa con las mujeres jóvenes? ¿Y con las mujeres de edad avanzada? En fin, nos faltan herramientas para pensar en la interrelación entre grupos etarios. Yo tengo una nieta, que estudia sociología, y que dice que es heredera del feminismo de su abuela. Mis hijas tienen incorporado el feminismo como el aire que respiran, no así mi hijo, que manifiesta algunas resistencias...

Hay mucho para pensar en este campo que nos ofrece debates y controversias, y más para seguir avanzando y participando en la sociedad en la que vivimos. Vos sabés que un lema del feminismo es hacer visible lo invisible. Y otro del psicoanálisis es hacer consciente lo inconsciente. Y en eso nos parecemos. Y tanto el psicoanálisis como los Estudios de Género tienen un proyecto de transformación, el psicoanálisis en lo personal, y los Estudios de Género en lo social y en las subjetividades, en lograr lazos más justos y equitativos entre los géneros. 
PALAVRAS. Revista de Epistemología, Metodología y Ética del Psicoanálisis

\section{E: Muchas gracias por tus palabras, Mabel.}

MB: Gracias a vos, por interesarte tanto. 